\title{
Direct Torque Control of Induction Motor Drives
}

\author{
Mr. Ravindra Pawar ${ }^{1}$, Prof. Ashok Jhala ${ }^{2}$ \\ M.Tech Research Student, RKDF college of Engineering, Bhopal ${ }^{1}$ \\ Head of the Department (Elect. \& Electronics Engg) RKDF college of Engineering, Bhopal ${ }^{2}$
}

\begin{abstract}
This paper presents improved performance of Direct Torque Control (DTC) of induction motor drives. At the time of switching DTC drive gives the high torque ripple. In DTC induction motor drive there are torque and flux ripples because of incorrect voltage vector selection by VSI states is unable to generate the exact voltage value required to make zero both the torque electromagnetic error and the stator flux error. To overcome this problem a Fuzzy Logic Controller is proposed. The fuzzy logic controller is used to reducing the torque and flux ripples and it improve performance DTC especially at low speed.
\end{abstract}

Keywords: direct torque control, induction motor, fuzzy logic, torque ripple minimization, fuzzy logic controller.

\section{INTRODUCTION}

Increasing The Induction Motor (IM) drives controlled of co-ordinates transform, Absences of mechanical with the vector control method has mostly accepted in the transducers, Current regulators, PWM pulse generation, PI industry. However, this control technique requires control of flux and torque and co-ordinate transformation complex coordinate transformation, inner current control are not required, Very simple control scheme and low loop and accurate system parameters. On the other hand, computation time, Reduced parameters sensitivity, Very the Direct Torque Control (DTC) method provides robust good dynamic properties. Conventional DTC has also and fast torque response without such coordinate some disadvantages: Possible problems during starting and transformation, PWM pulse generation and current low speed operation, High requirements upon flux and regulators. Moreover, DTC minimizes the use of motor torque estimation, Variable switching frequency. These parameters technique suffers from a major disadvantage of are disadvantages that we want to remove by using fuzzy steady state ripple in torque and flux, because none of the logic.

inverter-switching vector is able to generate the exact stator voltage at proper instants as well as in space. These torque and flux ripples affect the accuracy of speed estimation; result in high acoustic noise and harmonic losses. There are many methods to reduce this torque and flux ripple: (a) the alternative inverter topologies, multilevel inverters and matrix converters which increase the number of switches, and thus cost and complexity; (b) the higher switching frequencies reduce the harmonic content of stator current and thus torque and flux ripple. However, such higher switching frequencies lead to increased switching losses and stress on semiconductor switches of the inverter (c) yet, another method of reducing torque and flux ripples is fuzzy logic controller gives constant switching frequency. Moreover this method requires complex control schemes than classical DTC and is machine parameter dependent

DTC drive over the last decade becomes one possible alternative to the well-known Vector Control of Induction Machines. Its main characteristic is the good performance, obtaining results as good as the classical vector control but with several advantages based on its simpler structure and control diagram. DTC (Direct Torque Control) is characterized, as deduced from the name, by directly controlled torque and flux and indirectly controlled stator current and voltage. The DTC has some advantages in comparison with the conventional vector-controlled drives, like: Direct torque control and direct stator flux control, Indirect control of stator currents and voltages, Approximately sinusoidal stator fluxes and stator currents, High dynamic performance even at locked rotor, Absences

\section{DTC SCHEMATIC}

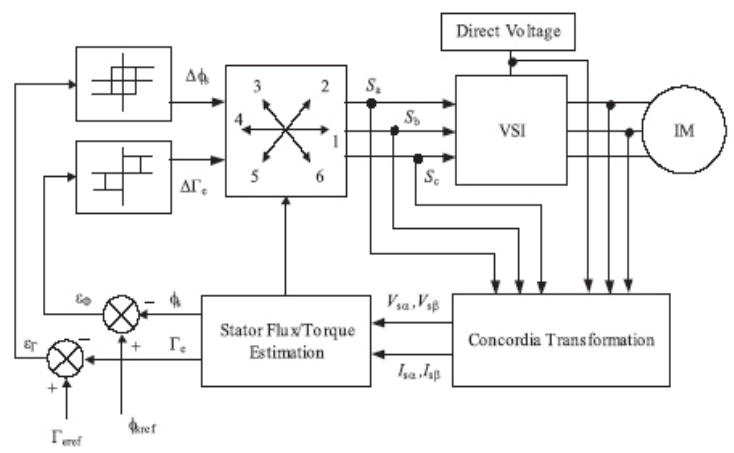

Fig.1 Block diagram of DTC scheme

DTC scheme is given in Fig. 1, the $\epsilon_{\Phi}$ and $\epsilon_{\tau}$ signals are delivered to two hysteresis comparators. The corresponding digitized output variables: change of magnetic flux $\Delta_{\Phi}$, of mechanical torque $\Delta_{\tau e}$ and the stator flux position sector $S_{N}$ created a digital word, which selects the appropriate voltage vector from the switching table.

The selection table generates pulses $S_{a}, S_{b}, S_{c}$, to control the power switches in the inverter. Three-level torque and two level flux hysteresis controllers are used according to the outputs of the torque controller and the sector information $S_{\Phi}$ of $\Phi_{S}$, , appropriate voltage vectors for both the inverters are selected from a switching table as it is shown in fig. 2 
INTERNATIONAL JOURNAL OF INNOVATIVE RESEARCH IN ELECTRICAL, ELECTRONICS, INSTRUMENTATION AND CONTROL ENGINEERING Vol. 4, Issue 1, January 2016

\begin{tabular}{|c|c|c|c|c|c|c|c|}
\hline Flux & Torque & \multicolumn{5}{|c|}{ Sector S $\varphi$} \\
\hline$\Delta \varphi$ & $\Delta \tau$ & S $\varphi 1$ & S $\varphi 2$ & S $\varphi 3$ & S $\varphi 4$ & S $\varphi 5$ & S $\varphi 6$ \\
\hline 1 & 1 & V2 & V3 & V4 & V5 & V6 & V1 \\
\hline 1 & 0 & V7 & V0 & V7 & V0 & V7 & V0 \\
\hline 1 & -1 & V6 & V1 & V2 & V3 & V4 & V5 \\
\hline-1 & 1 & V3 & V4 & V5 & V6 & V1 & V2 \\
\hline-1 & 0 & V0 & V7 & V0 & V7 & V0 & V7 \\
\hline-1 & -1 & V5 & V6 & V1 & V2 & V3 & V4 \\
\hline
\end{tabular}

Fig.2 Classical DTC switching table

Figure.3.5shows the voltage vectors which are usually employed in DTC scheme when the stator flux vector is lying sector I is shown in fig 3.8. The selection of a voltage vector at each cycle period is made in order to maintain the torque and the stator flux within the limits of two hysteresis bands. This simple approach allows a quick torque response to be achieved, but the steady state performance is characterized by undesirable ripple in current, flux and torque. This behaviour is mainly due to the absence of information about torque and rotor speed values in the voltage selection algorithm.

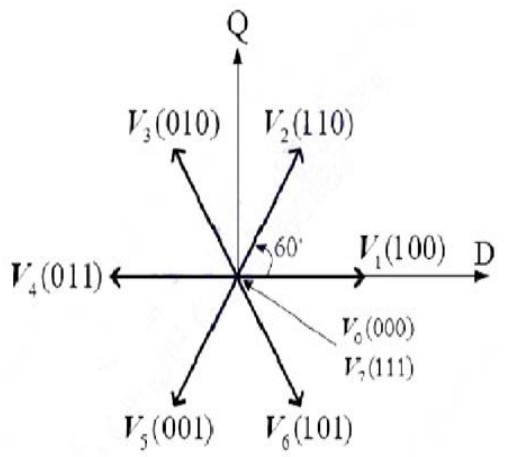

Fig.3 Eight possible voltage space vectors

\section{VECTOR TRANSFORMATIONS}

Concordia transformation for voltages

By using this transformation, two voltages $\mathrm{V}_{\mathrm{sd}}$ and $\mathrm{V}_{\mathrm{sq}}$ are obtained. The measured voltage $\mathrm{U} 0$ is necessary and the switching table also $S_{a}, S_{b}, S_{c}$.

$$
\begin{gathered}
\mathrm{V}_{\mathrm{sd}}=\sqrt{\frac{2}{3}} \mathrm{U}_{0}\left(\mathrm{~S}_{\mathrm{a}}-\frac{1}{2}\left(\mathrm{~S}_{\mathrm{b}}+\mathrm{S}_{\mathrm{c}}\right)\right) \\
\mathrm{V}_{\mathrm{sq}}=\frac{1}{\sqrt{2}} \mathrm{U}_{0}\left(\mathrm{~S}_{\mathrm{b}}-\mathrm{S}_{\mathrm{c}}\right)
\end{gathered}
$$

\subsubsection{Concordia transformation for currents}

This transformation is used to obtain currents $I_{s d}$ and $I_{s q}$, after measures of $I_{s a}, I_{s b}$ and $I_{s c}$ of the stator.

$$
\begin{gathered}
I_{s d}=\sqrt{\frac{3}{2}} I_{s a} \\
I_{s q}=\frac{1}{\sqrt{2}}\left(I_{s b}-I_{s c}\right)
\end{gathered}
$$

\subsubsection{Flux and torque estimations}

DTC command is based on estimation in flux and in torque. In order to realize these estimators, we used results of Concordia transformations.

Because stator voltage is define by:

$$
\mathrm{Vs}=\mathrm{Rs} * \mathrm{Is}+(\mathrm{d} \varphi \mathrm{s} / \mathrm{dt})
$$

We have

$$
\varphi_{\mathrm{s}}=\int \mathrm{Vs}-\mathrm{Rs} * \mathrm{Is}
$$

That's why, we have two equations:

$$
\begin{aligned}
& \Phi_{s d}=\int_{0}^{t}\left(V_{s d}-R_{s} I_{s d}\right) d t \\
& \Phi_{s q}=\int_{0}^{t}\left(V_{s q}-R_{s} I_{s q}\right) d t
\end{aligned}
$$

We can now estimate torque,

$$
\tau_{\mathrm{e}}=\mathrm{p}\left[\Phi_{\mathrm{sd}} \mathrm{I}_{\mathrm{sq}}-\Phi_{\mathrm{sq}} \mathrm{I}_{\mathrm{sd}}\right]
$$

\section{DTC CONTROLLER}

The way to impose the required stator flux is by means of choosing the most suitable Voltage Source Inverter state. If the ohmic drops are neglected for simplicity, then the stator voltage impresses directly the stator flux in accordance with the following equation:

Or

$$
\frac{\mathrm{d}}{\mathrm{dt}} \bar{\psi}_{\mathrm{s}}=\overline{\mathrm{u}}_{\mathrm{s}}
$$

$$
\overline{\Delta \psi}_{\mathrm{s}}=\overline{\mathrm{u}}_{\mathrm{s}} \Delta \mathrm{t}
$$

Decoupled control of the stator flux modulus and torque is achieved by acting on the radial and tangential components respectively of the stator flux-linkage space vector in its locus. These two components are directly proportional $\left(R_{s}=0\right)$ to the components of the same voltage space vector in the same directions

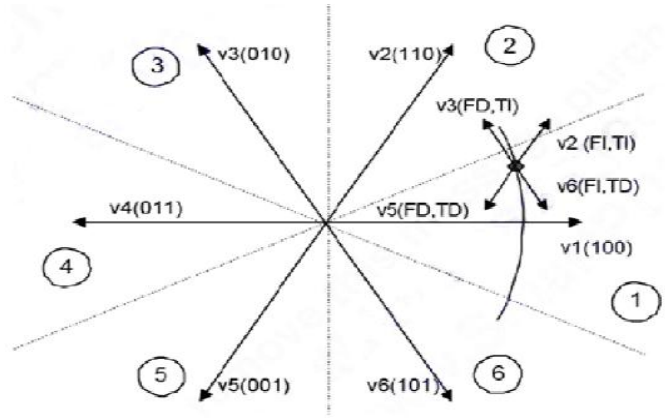

Fig-1: Stator flux vector locus

The hysteresis band has to be set large enough to limit the inverter switching frequency below a certain level that is usually determined by thermal restriction of power devices. Since the hysteresis bands are set to cope with the worst case, the system performance is inevitably degraded in a certain operating range, especially in a low speed region. In torque hysteresis controller, an elapsing time to move from lower to upper limit, and vice versa can be changed according to operating condition. 
INTERNATIONAL JOURNAL OF INNOVATIVE RESEARCH IN ELECTRICAL, ELECTRONICS, INSTRUMENTATION AND CONTROL ENGINEERING Vol. 4, Issue 1, January 2016

SIMULATED RESULTS for DTC Model

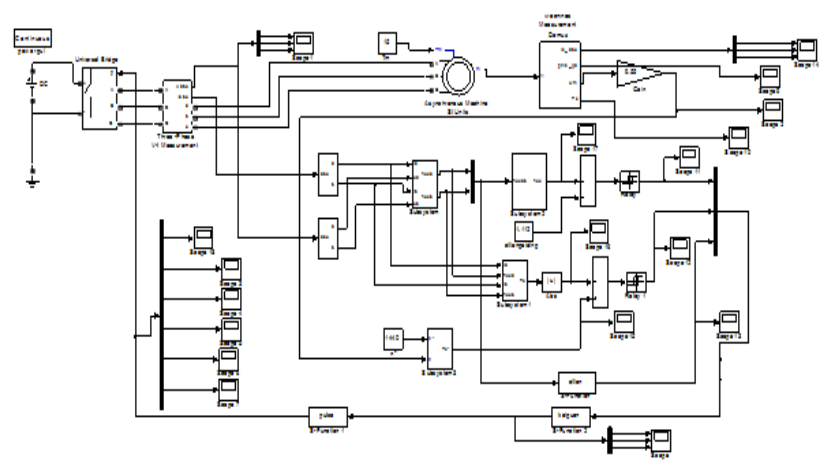

Figure 4.8: Direct Torque Control of Induction Schematic using SIMULINK/MATLAB.

\section{V.SIMULATION}

Motor characteristics

The rating of induction motor is $5 \mathrm{Hp}, 415 \mathrm{~V}, 50 \mathrm{~Hz}, 1430$ rpm star connected induction motor. For all simulation, the motor characteristics will be utilized as below:

Stator Resistance $(\mathrm{ohm}) \quad=1.405$

Rotor Resistance $(\mathrm{ohm})=1.395$

Stator Self Inductance $(\mathrm{H})=0.005839$

Rotor Self Inductance $(\mathrm{H})=0.005839$

Mutual Inductance $(\mathrm{H}) \quad=0.2037$

No. of poles $\quad=4$

Moment of Inertia $\left(\mathrm{kg} \cdot \mathrm{m}^{\wedge} 2\right)=0.03$

Load torque $(\mathrm{Nm}) \quad=15$

Sampling time, $(\mathrm{Ts}) \quad=1 \mathrm{sec}$

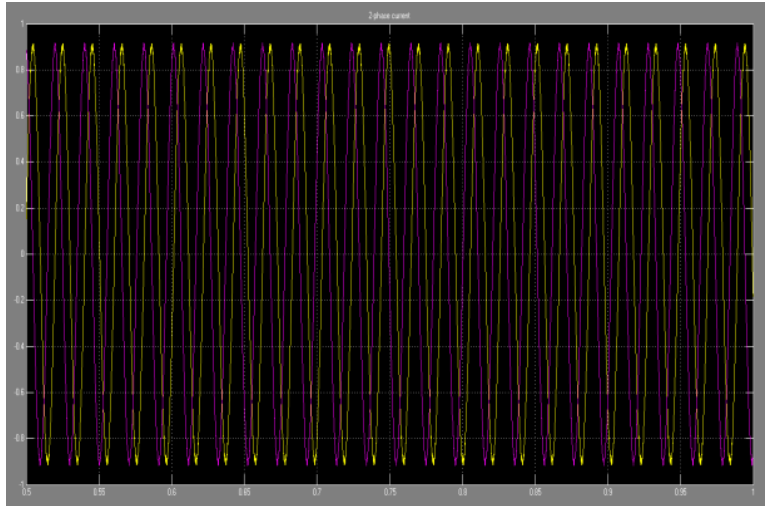

Fig 4.13: 2-phase current in DTC

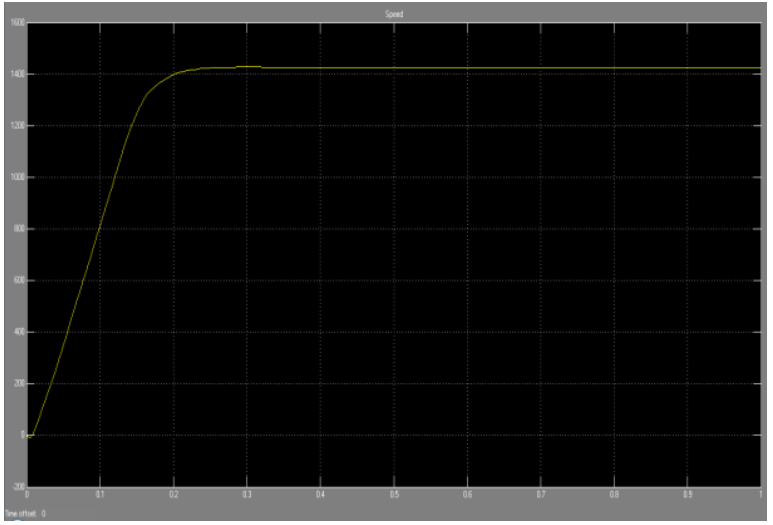

4.14 Fig: Speed in DTC

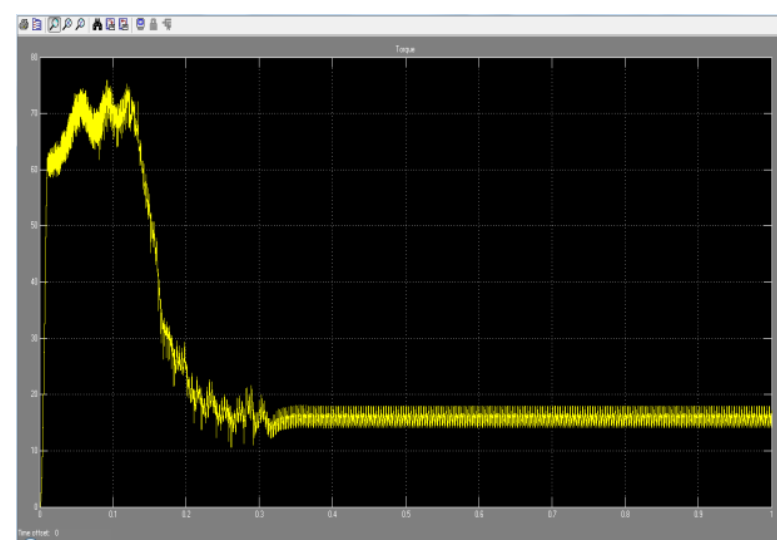

Fig 4.15: Torque in DTC

The simulations of the DTC induction motor drive were carried out using the Matlab/Simulink simulation package. From figure torque ripple is significantly reduced when DTC used. Also DTC gives better performance not only at lock rotor but also at standstill. It is seen that the steady state performance of the DTC.

\subsection{Study Case:}

a) For DTC model:
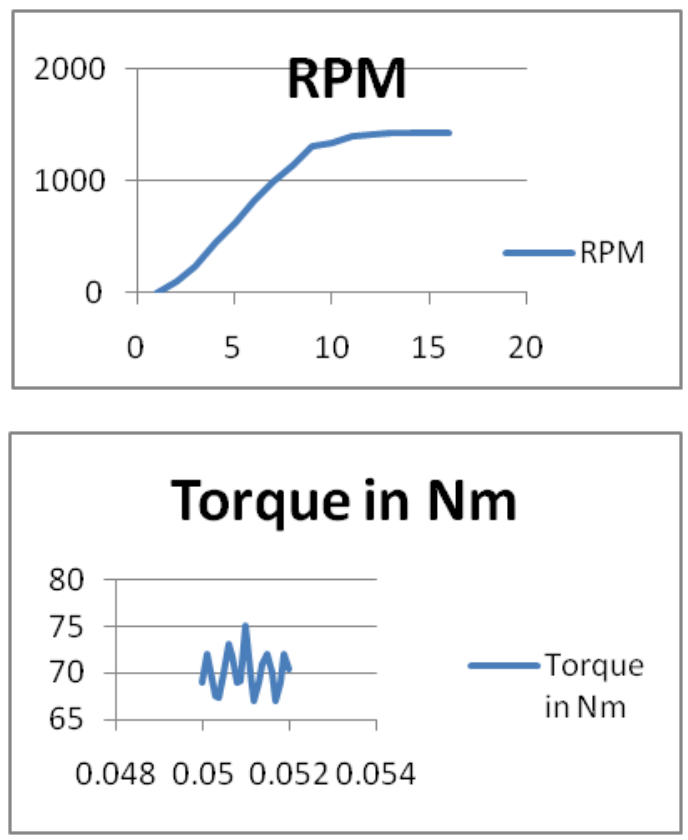

\section{CONCLUSION}

For any IM drives, direct torque control is one of the best controllers proposed so far. It allows decoupled control of motor stator flux and electromagnetic torque. From the analysis it is proved that, this strategy of IM control is simpler to implement than other vector control methods as it does not require pulse width modulator and co-ordinate transformations. But it introduces undesired torque and current ripple. DTC scheme uses stationary d-q reference frame with d-axis aligned with the stator axis. Stator voltage space vector defined in this reference frame control the torque and flux. The main inferences from this work are: 
1. In transient state, by selecting the fastest accelerating voltage vector which produces maximum slip frequency, highest torque response can be obtained.

2. In steady state, the torque can be maintained constant with small switching frequency by the torque hysteresis comparator by selecting the accelerating vector and the zero voltage vectors alternately.

3. In order to get the optimum efficiency in steady state and the highest torque response in transient state at the same time, the flux level can be automatically adjusted.

4. If the switching frequency is extremely low, the control circuit makes some drift which can be compensated easily to minimize the machine parameter variation.

The estimation accuracy of stator flux is very much essential which mostly depends on stator resistance because an error in stator flux estimation will affect the behaviour of both torque and flux control loops. The torque and current ripple can be minimized by fuzzy logic controller technique.

\section{REFERENCES}

[1] B. K.Bose. 1997. Power Electronics and Variable Frequency Drives. IEEE Press, New York.

[2] Kazmierkowski, R.Krishnan, Blaabjerg, Control in Power Electronics, Selected Problems

[3] Takahashi Isao, Noguc hi Tos hihiko, „A New Quick-Response and High-Efficiency Control Strategy of an Induction Motor ${ }^{\text {ecee }}$, IEEE Transactions on Industry Applications, Vol. IA-22 No-5, Sept/Oct 1986.

[4] Thomas G.Habetler, Francesco Profumo, Michele Pastorelli and Leon M. Tolbert "Direct Torque Control of IM us ing Space Vector Modulation" IEEE Transactions on Industry Applications, Vol.28, No.5, Sept/Oct 1992.

[5] E.Bassi, P. Benzi, S. Buja, "A Field Orientation Scheme for Current-Fed Induction Motor Drives Based on the Torque Angle Closed-Loop Control' IEEE Transactions on Industry Applications, Vol. 28, No. 5, Sept./ Oct. 1992.

[6] James N. Nash, "Direct Torque Control, Induction Motor Vector Control Without an encoder" IEEE Trasaction on Industry applications,Vol.33,No.2,March/April 1997.

[7] M. Depenbrock, " ${ }^{\text {DD }}$ irect Self-Control (DSC) of Inverter-Fed Induction Machine eeee, IEEE Transactions on Power Electronics, Vol.3, No.4, Oct.1988.

[8] Cristian Lascu, Boldea, Blaabjerg "A Modified Direct Torque Control for Induction Motor Sensorless Drive" IEEE transaction on Industry Applications, Vol.36, No.1, Jan/Feb 2000.

[9] Anthony Purcell, P. Acarnley, "Enhanced Inverter Switching for Fast Response Direct Torque Control" IEEE Transactions on Power Electronics, Vol. 16, No. 3, may 2001.

[10] M.Vasudevan, R.Arumugam "New Direct Torque Control Scheme of Induction Motor for Electric vehic le" Proceeding of control conference,5th Asian,Vol.2, 2004.

[11] M.Vasudevan, R.Arumugam, S.Paramasivam“ High performance adaptive Inte lligent DTC Schemes for induction motor drives" SJEE, Vol.2, No1,May 2005.

[12] Sarat K. Sahoo, G. Tulsi Ram Das, Vedam Subrahmanyam "Implementation and Simulation of DTC scheme with the use of FPGA scheme" ARPN Journal of Engineering and Applied Sciences, Vol.3. No.2, April 2008.

[13] Ehsan Hassankhan, Davood A. Khaburi,'DTC-SVM Scheme for Induction Motors Fed with a Three-level Inverter", World Academy of Science, Engineering and Technology 2008.

[14] L. Bouras, M. Kadjoudj, "Vector control of induction motor based Space Vector Modulation" Electronics and Telecommunications, Vol.50, No.1, 2009.

[15] Prof.K.B.Mohanty "A Direct Torque Controlled Induction Motor with Variable Hysteresis Band" 11th International Conference on Computer Modelling and Simulation, UK Sim 2009.

[16] Zhifeng Zhang, Renyuan Tang, "Novel Direct Torque Control Based on Space Vector With Modulation Adaptive Stator Flux
Observer for Induction Motors" IEEE Transactions on Magnetics, Vol. 46, No. 8, August 2010.

[17] T.Nasser et al, "direct torque control of induction motor based on artificial neural networks With estimate and regulation speed using the MRAS and neural pi controller" Journal of Theoretical and Applied Information Technology" 2010.

[18] S Allirani, V Jagannathan, "High Performance Direct Torque Control of Induction Motor Drives Using Space Vector Modulation" IJCSI, Vol. 7, Issue 6, November 2010.

[19] K. Kaur, S. Duvvuri, S. Singh, "Simulation of Indirect Vector Controlled Induction Motor Drive" IEEE International Conference on Advanced Computing \& Comm.Techno.2011.

[20] Giovanna Oriti and Alexander L. Julian,"Three-Phase VSI with FPGA-Based Multisampled Space Vector modulation" IEEE transactions on industry applications, Vol. 47, No. 4, July/August 2011.

[21] AuzaniJ idin, NikIdris, Mohamed Yatim, "Simple Dynamic Overmodulation Strategy For Fast Torque Control in DTC of Induction Machines With Constant-Switching-Frequency Controller'IEEE transactions on industry applications, Vol. 47, No. 5, Sept/Oct 2011.

[22] A. Mishra, P.Choudhary, "Speed Control Of An Induction Motor By Using Indirect Vector Control Method" IJETAE,Volume 2, Issue 12, December 2012.

[23] H. Arabaci and O. Bilgin, "Squirrel Cage of Induction Motors Simulation via Simulink" International Journal of Modeling and Optimization, Vol. 2, No. 3, June 2012.

[24] Sifat Shah, A. Rashid, MKL Bhatti, "Direct Quadrate (D-Q) Modeling of 3-Phase Induction Motor Using MatLab / Simulink" Canadian Journal on Electrical and Electronics Engineering Vol. 3, No. 5, May 2012.

[25] Nasir Uddin, Muhammad Hafeez, "FLC-Based DTC Scheme to Improve the Dynamic Performance of an IM Drive" IEEE transactions on industry applications, Vol. 48, No. 2 March/April 2012 . 